\title{
The Semantic Evolution of Verb "Sit" in Southwest Mandarin
}

\begin{abstract}
Xiaoni $\mathrm{Hu}^{1, \mathrm{a}}$
${ }^{1}$ Chongqing Foreign Language School

3240023851@qq.com

ABSTRACT

With the opening up of commercial ports in riverside cities such as Chongqing more than one hundred years ago, many Western missionaries gradually went deep into Yunnan, Guizhou and Sichuan areas and compiled several local language textbooks for later generations, which also provided valuable materials for dialect scholars to study Southwest Mandarin a hundred years ago. The author specifically analyzes on the basis of spoken examples in books written in West Sichuan dialects and Sichuan dialects dictionary, as well as in the four major administrative regions of Chongqing Yubei District, Guizhou Yunyan District, Chengdu Qingyang District, and Kunming Panlong District, China, and seeks to clearly dissect the pragmatic full picture of the verb "sit" in southwestern languages, using the "lexical semantic dynamic pattern" to interrogate its semantic changes over the centuries. The interpretation and usage of the word "sit" not only changes with the historical changes in Southwest China, but also influences the investigation and research of modern Chinese lexicology to a certain extent.
\end{abstract}

Keywords: Southwest Mandarin, "Sit", Semantic Evolution

\section{INTRODUCTION}

The definition of southwestern mandarins given in the Chinese Language Atlas is as follows: in the Southwest region and its vicinity, the entering tone is wholly assigned to a certain tone or four-tone value similar to the Chinese dialects of Chengdu, Wuhan, Chongqing, Changde, Guiyang, Kunming and Guilin. With as many as 270 million people in use, the southwestern language is the most widely used and populous one, and is considered an extension of Jianghuai Mandarin by dialects scholars, both of whom have origins and belong to Southern family mandarins. According to historical studies, the formation of southwestern mandarins began during the Ming Dynasty as a gradual formation of vernacular dialects resulting from the influx of numerous immigrants into the southwest, whereby immigration is a major factor in the formation of southwestern mandarins. The formation of southwestern mandarins is of great relevance to the migrations that entered Southwest China after the Yuan Dynasty. Given that the ages at which Sichuan languages in the Chengdu Chongqing region diverged from Wuhan speakers in the Hunan Hubei Guangzhou region can be traced at least back to the Ming Dynasty, the earlier the formation of the Southwestern Mandarin should be considered, although its basic vocabulary and grammatical rules are quite different from those of mandarins, there are also a large number of dialects that are different from Mandarin vocabulary, as well as some special grammatical case. The interpretation of the verb "sit" in the seventh edition of the Modern Chinese Dictionary comes from Southwest Mandarin, and almost all of them are real words. However, up to now, no one has described the "sit" in Southwest Mandarin in detail, nor has a comprehensive comparative study been made on the differences between Southwest dialect vocabulary and Mandarin vocabulary. Therefore, the author believes that this study can provide some informative data for the study of Southwest Mandarin for reference.

In the process of constructing the conceptual space, we were able to discover a hundred years ago that the semantic chain formed by the Southwestern Mandarin "sit" in each region is not disorganized, but has certain boundaries and laws, the totality of which can be summarized in two paths: actions and states, and, at the same time, there are also overlapping parts between the two paths. Each of these will be analyzed below. 


\section{THOUGHTS, METHODS AND BASIC STEPS OF THIS STUDY}

\subsection{Research Ideas}

Based on linguistic theory, lexical theory, cultural linguistics and contrastive linguistic theory, this study uses traditional dialect description methods and social survey statistics to describe "sit" in Southwest Mandarin in detail. Then, this paper uses comparative analysis and inductive method to study the difference of "sit" between Southwest Mandarin and Putonghua respectively from the linguistic and cultural perspectives, and to analyze the reasons for the difference.

This study is divided into six chapters to elaborate the "sit" and its derivative potential in Southwest Mandarin: The first chapter is the introduction, which introduces the research status of Southwest Mandarin and "sit"; The second chapter explains the purpose, significance, ideas and methods of the research; The third chapter presents the overall appearance of "sit" in Southwest Mandarin 100 years ago by means of list, and compares it with "sit" in modern southwest mandarin after referring to the historical evolution; The fourth chapter mainly describes the current situation of the word "sit" in four different dialects, and speculates that southwest mandarin occupies a considerable position in the compilation of modern Chinese dictionaries; The fifth chapter looks at the commonness and individuality of the semantic evolution of "sit" from a cross language perspective; The sixth chapter is the conclusion. Through this study, the semantic evolution of "sit" in Southwest Mandarin over 100 years and its possible internal and external causes can be obtained, which will provide more detailed data and evidence for the future study of Southwest Mandarin vocabulary.

\subsection{Material sources of this study}

\subsubsection{Identification of investigative sites}

Due to the epidemic situation, this study mainly focused on questionnaire survey, using the survey of $\mathrm{Wu}$ dialect of Zhejiang University as the blueprint, and issued an interview notice for native speakers of dialects on the Internet. Since the author himself is a person of Chongqing, live in Yubei District, corpus collection in Yubei District of Chongqing is performed offline.

\subsubsection{Corpus collection}

First step: find a suitable native speaker for dialects.

1) Respondents at survey sites in Yubei District of Chongqing:

(1Hu Wensheng, male, 53 years old, computer engineer, undergraduate, bachelor of engineering, has lived in Yubei district for a long time, having lived in Suzhou four years.

(2) Yang Li, female, 52 years old, business manager, undergraduate, bachelor of engineering, has lived in Yubei district for a long year without a history of living in other dialects.

(3) He Yuanling, female, 17 years old, high school student, the main living areas are Yubei district and Chongqing Foreign Language School (Jiulongpo district), with no departure from Chongqing dialects.

2) Respondents at the survey site of Chengdu Qingyang District:

(1Feng Xiangtai, male, 18 years old, freshman, has lived in Qingyang District for a long time without a history of residence in other dialects areas.

(2) i Xinyue, female, 26 years old, office lady, undergraduate, long life in Qingyang District, no history of living in other dialects.

(3) $\mathrm{Lu}$ Yiping, female, 49 years old, employee, junior college education level, the main living area is Qingyang District, no history of living in other dialect areas.

3) Respondents at the survey site of Guiyang Yunyan District :

1Chen Bixia, female, 78 years old, primary school teacher (retired), high school education level, has long lived in Yunyan District and has a living history of Tongzi County, Zunyi.

(2) Zhai Moran, male, 17 years old, high school student, has long lived in Yunyan District, no history of living in other dialects areas.

(3) Zhang Qinghong, male, 32 years old, community staff, undergraduate, has always lived in Guiyang Yunyan District.

4) Respondents at the survey site in Panlong District, Kunming:

(1) Song Ping, female, 60 years old, retired cadre, undergraduate, has been living in Kunming, Yunnan Province.

(2) Yang Linyuan, male, 29 years old, secondary school teacher, graduate, and has long lived in Kunming Panlong District.

(3) Li Xuefeng, female, 16 years old, senior high school student, has long lived in Kunming and studied in Huicheng middle school, Panlong District, Kunming.

Step 2: Data collection.

After identifying a certain verb in the southwestern vernacular about a hundred years ago as a major direction of inquiry, the author contacted volunteers 
(pseudonymized "Bing Guo") in the cultural preservation organization of Chongqing, who were offered the opportunity to freely borrow records or annals. Chongqing successive local records integration is a large local records literature series, prepared by the Chongqing Office of records or annals, published by the National Library Press, with a total of 100 books. A total of 128 local records in the Chongqing region from Chenghua year in Ming Dynasty to the Republic of China were included, involving prefectures, states, prefectures, and counties, including 5 local records during the Ming Dynasty, 92 local records during the Qing Dynasty, and 31 local records during the Republic of China, of which 28 Local records were solitary copies. Meanwhile, the series was compiled with 11 chorograms and local records sections in the literature about Chongqing,Including the Chronicles of Huayang, Unified Records of the Ming Dynasty, Sichuan Annals [Yongzheng], Sichuan Annals [Jiaqing], Unified Records of the Qing Dynasty, Reworking Sichuan Annals Draft [Republic of China], Compendium of local chronicles of Sichuan Province [Republic of China], Food and goods records of Fengjie County [Republic of China], Records of scenic spots in Sichuan, Sichuan scenery, Collections and correction of Sichuan scenery, etc. Unfortunately, however, the series had few parts on dialects, combined with the fact that the volume of material was too large, and the author tried to abandon the idea of starting the investigation from local records or annals all over the country. After being advised by mentor, the author directly searched all works left by missionaries who were engaged in activities in the Southwest after Chongqing opened up as a commercial port on the market, which were very targeted.

\subsubsection{Investigation method}

The author first collated the items pertaining to "sit" in a book in Western Shu dialects as a questionnaire (see "Investigation and Analysis of Verb 'sit' in Four Dialect Points of Modern Southwest Mandarin" below), and then respondents were asked to mark in the unit of the item still in use within the form before archiving it to the same form for visual comparison. During the process of grooming the corpus, three respondents from Chengdu Qingyang District feedback results appeared divergent on the term "mounting", for which the author read the relevant chapter of "Hu Guang fills Sichuan" in the book of ancient Chengdu and the book of Chengdu Qingyang District Chronicle 1991-2005, and found that both had explicitly mentioned the concept of "mounting", from which it was decided to retain the term.

\section{COMPARING THE EXPLANATIONS OF VERB "SIT" IN MAJOR LITERATURES}

\subsection{Basic Data of Southwest Mandarin}

The author lists the "sit" meaning in Southwest Mandarin a hundred years ago as the following table with reference to the original grammar example sentences in Xishu Dialect and West China Chinese Textbook (also known as English is a perfect match for century old Sichuan dialect) and the notes and translations of later scholars.

Table 1 The Meaning and Use of "Sit" in Southwest Mandarin a Hundred Years Ago

\begin{tabular}{|c|c|c|c|c|}
\hline $\begin{array}{l}\text { Meaning of } \\
\text { "sit" }\end{array}$ & Example sentence & $\begin{array}{l}\text { Translation of Example } \\
\text { Sentences in Modern Chinese }\end{array}$ & $\begin{array}{l}\text { Does the Modern } \\
\text { Chinese } \\
\text { Dictionary (7th } \\
\text { Edition) still retain } \\
\text { the meaning and } \\
\text { usage? }\end{array}$ & $\begin{array}{l}\text { The chain of } \\
\text { relations } \\
\text { corresponding } \\
\text { in a thought } \\
\text { guide diagram }\end{array}$ \\
\hline $\begin{array}{l}\text { Place hips on } \\
\text { objects }\end{array}$ & $\begin{array}{l}\text { Please sit with your left } \\
\text { hand down. } \\
\text { Manager, please take a } \\
\text { seat in the living room. }\end{array}$ & $\begin{array}{l}\text { Please sit on the left side. } \\
\text { Guest, please sit (rest) in the } \\
\text { living room. }\end{array}$ & yes & 1) (1) \\
\hline Ride & $\begin{array}{l}\text { Travel in a sedan chair. } \\
\text { Bring the mount over. } \\
\text { Lift the sedan chair down } \\
\text { and I want to sit }\end{array}$ & $\begin{array}{l}\text { Travel a long distance in a } \\
\text { sedan chair. } \\
\text { Bring the mount over. } \\
\text { Stop the sedan chair and I'm } \\
\text { going to get on it. }\end{array}$ & yes & 1) (2) \\
\hline Live & $\begin{array}{l}\text { Where do you sit? } \\
\text { Sit on Tongsi street at the } \\
\text { north gate. }\end{array}$ & $\begin{array}{l}\text { Where do you live? } \\
\text { Live in Tongsi street near the } \\
\text { north gate. }\end{array}$ & yes & 2) (4) \\
\hline $\begin{array}{l}\text { Place the } \\
\text { item on the } \\
\text { fire and heat } \\
\text { it }\end{array}$ & $\begin{array}{l}\text { Sit the water on. } \\
\text { Fried eggs, first sit on the } \\
\text { pan. } \\
\text { Early the following day, } \\
\text { sit and open. } \\
\text { With boiling milk jars, sit } \\
\text { the milk. }\end{array}$ & $\begin{array}{l}\text { Heat water (pot) to boiling. } \\
\text { Preheat the pan before frying } \\
\text { the eggs. } \\
\text { The next morning, put the } \\
\text { porridge on the stove and boil it. } \\
\text { Boil the milk in the milk can. }\end{array}$ & yes & 1) (7) \\
\hline
\end{tabular}




\begin{tabular}{|l|l|l|l|l|}
\hline "Seat" & $\begin{array}{l}\text { Have a seat? } \\
\text { No seat }\end{array}$ & $\begin{array}{l}\text { Are there seats available? } \\
\text { There are no seats. }\end{array}$ & yes & 1) (6) \\
\hline $\begin{array}{l}\text { In a state of } \\
\text { imprisonment }\end{array}$ & sit in prison & be in prison & 2) (4) \\
\hline $\begin{array}{l}\text { The state of } \\
\text { rest after } \\
\text { childbirth }\end{array}$ & month sitting & $\begin{array}{l}\text { Moon sitting: A woman's } \\
\text { reproductive organs and bodies } \\
\text { are restored to normal by } \\
\text { means of self-cultivation and } \\
\text { nourishment for a period of time } \\
\text { after childbirth. }\end{array}$ & yes & 2) (1) \\
\hline $\begin{array}{l}\text { Home } \\
\text { Ordinary Household }\end{array}$ & Sitting family & $\begin{array}{l}\text { Base of lamp } \\
\text { Meat on the hips of pigs }\end{array}$ & no & 2) (4) \\
\hline $\begin{array}{l}\text { The bottom, } \\
\text { something }\end{array}$ & Samp seat \\
\hline $\begin{array}{l}\text { To close or } \\
\text { repair. }\end{array}$ & $\begin{array}{l}\text { Seams seated the paint } \\
\text { tightly }\end{array}$ & Brush the cracks with paint. & no & 1 () (4) \\
\hline (height) short & Rice seedling sitting & $\begin{array}{l}\text { Crop seedlings are poorly } \\
\text { developed and very short }\end{array}$ & no & 1) (7) \\
\hline Price fall & Metric price seated & The price of rice has fallen. & no & 2 (1) \\
\hline $\begin{array}{l}\text { Building } \\
\text { Sinking }\end{array}$ & Sit down over the house & $\begin{array}{l}\text { The house collapsed over } \\
\text { there. }\end{array}$ & yes & 1) (3) \\
\hline $\begin{array}{l}\text { Get into a } \\
\text { situation }\end{array}$ & Get into trouble & no & 1 (3) (3) \\
\hline
\end{tabular}

These dentures do not exist in isolation. This pictorial diagram below is able to reflect how they relate to each other.

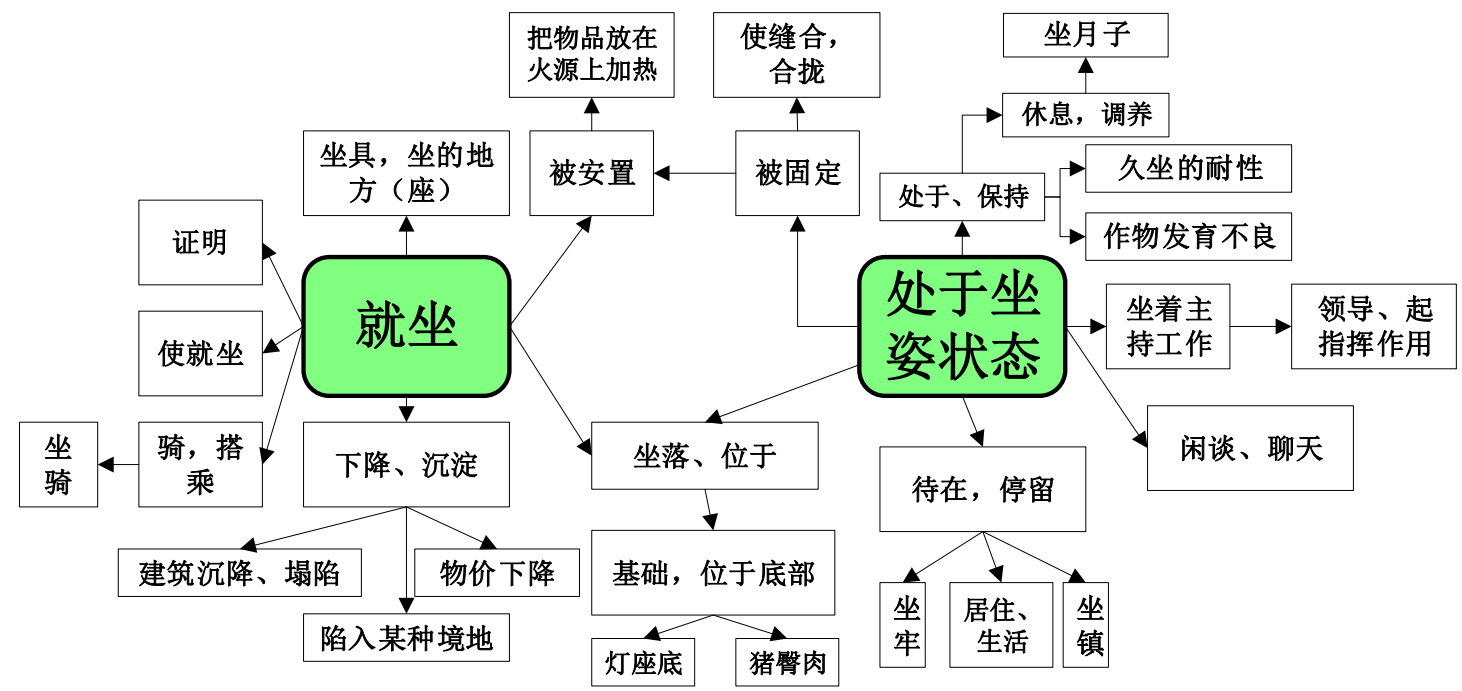

图 1 一百年前西南官话中“坐”的语义网络图 


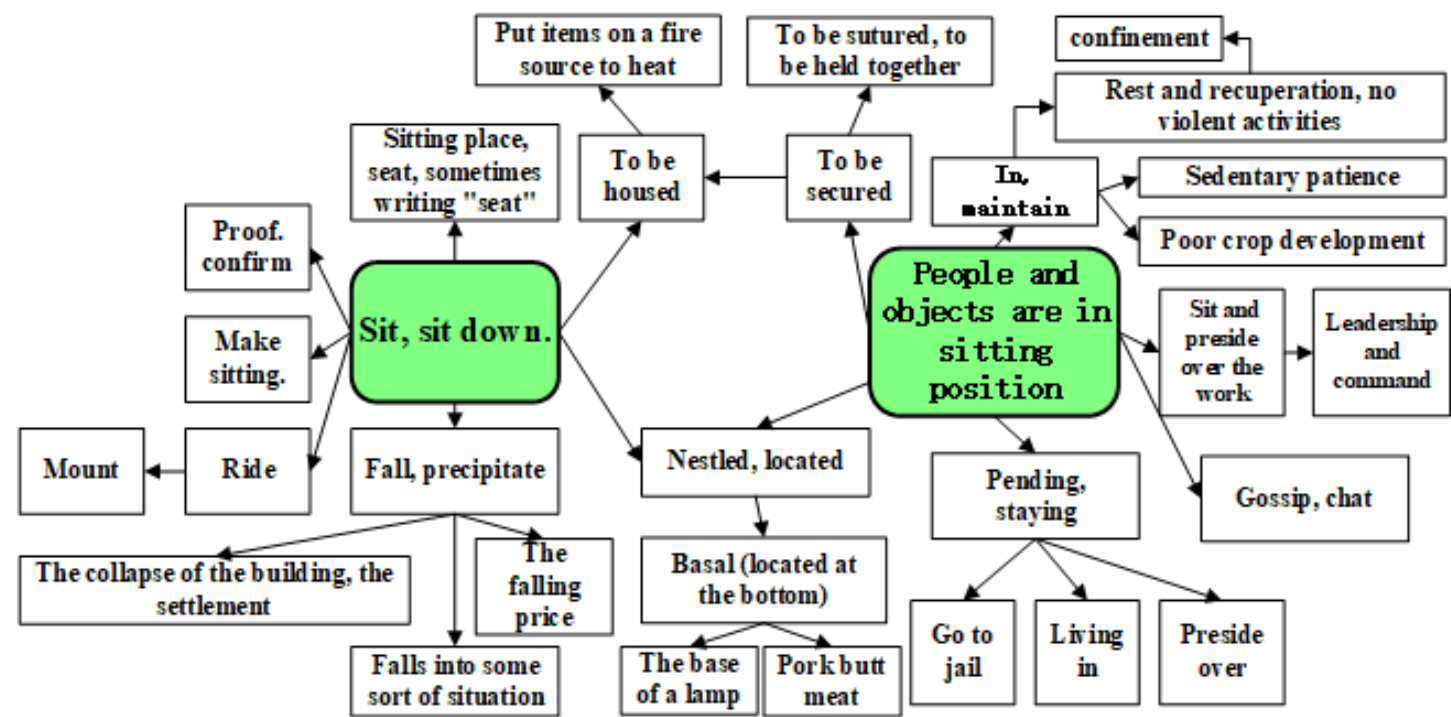

Figure 1 Semantic Network Diagram of Sit in Southwest Mandarin 110 Years ago

1) 就坐, 坐下。

1) Sit, sit down.

(1)使就坐。

(1)Make sitting.

(2)骑, 搭乘——坐骑。

(2) Ride, ride - mount.

(3)下降, 沉淀一建筑物的塌陷, 沉降——物价 下降一陷入某种境地。

(3) Fall, precipitate - the collapse of the building, the settlement - the falling price - falls into some sort of situation.

(4)坐落, 位于——基础（位于底部）。

(4) Nestled, located - basal (located at the bottom).

(5)证明。坐实。

(5) Proof. confirm.

6)坐的地方, 坐具, 有时写作“座”。

(6) Sitting place, seat, sometimes writing "seat".

(7)被安置——把物品放在火源上加热——被固定 一使缝合，合拢。

(7) To be housed - put items on a fire source to heat - to be secured - to be sutured, to be held together.

2）人、物处于坐姿状态

2) People and objects are in sitting position

(1)处于，保持一久坐的耐性一一作物发育不良 一休息调养，不事剧烈活动一一坐月子。

(1) In, maintain - sedentary patience - poor crop development - rest and recuperation, no violent activities - confinement.

(2)坐着主持工作一一领导，起指挥作用。

(2) Sit and preside over the work - leadership and command.

(3)闲谈, 聊天。

(3) Gossip, chat.

(4)待在, 停留一坐牢一一居住生活一坐镇。

(4) Pending, staying - go to jail - living in - preside over.

(5)坐落，位于。

(5) Nestled, located

6)被安置——被固定。

(6) Was placed - was fixed.

\subsection{Historical Evolution of Southwest Mandarin from Recent to Modern Times}

Before discussing modern southwestern mandarins, we must first make clear how the present-day southwestern mandarins have undergone more change than recent times.

The dominating vernaculars, both geographically and linguistically, are those of Sichuan and Chongqing dialects, as exemplified most strongly by the Folk Adage adaptation to transcripts in Shu Language. However, the current Sichuan dialects, which are not those of ancient Shuo people. Before the Ming Dynasty, after convergence of successive migrations, the Sichuan native dialects were gradually formed, at which time, as a whole of Sichuan, speech followed the present Wenjiang Chongzhou accent, a dialects that linguists call Nanlu languages. 
In the late Ming Dynasty, Zhang Xianzhong entered Sichuan, and years of war and indiscriminate killing created a huge population hole. In the early Qing Dynasty, a large-scale migration operation took place: "Huguang (Hunan province in the Qing Dynasty called Huguanghang province) filled Sichuan", and many people migrated to Sichuan from Hunan and Hubei, whereby the Huguang people covered most of the Sichuan area, and an alternative Sichuan dialects were formed: Huguang dialect.

Zhou Jixu (2016), a linguist of Sichuan Normal University, systematically studied Sichuan dialects in Chongqing and Sichuan, and considered that Sichuan dialects can be divided into two broad categories: Huguang dialect and Nanlu dialect. Previously, there was a view that Sichuan dialects evolved historically from Sichuan native words, but in practice, the Sichuan dialects were not continuous because they were cut off by the Ming terminal war during development. After Huguang filling Sichuan, Huguang covers Sichuan language, but does not replace it completely, but instead is bounded by Minjiang along the Minjiang northeast direction, with Hubei migrants from Hunan covering Chongqing first, then continuing towards the West and eventually reaching Chengdu. These migrants were distributed in Chongqing, Nanchong, Chengdu, and northeast of Chengdu, while their formed Sichuan dialects called Huguang dialects. However, due to the hindrance of the Minjiang, the West and south of the Minjiang, the wars brought by Zhang Xiangzhong were less disruptive, there was little migration, and Sichuan dialects that existed before the Ming period were preserved, such as Dayi, Qionglai, Wenjiang and Leshan, Zigong along the river to Yibin and Luzhou, and the Sichuan dialects spoken by the people of this piece are known as Nanlu dialect. According to Zhou Jixu (2016), Chongqing is the most authentic Huguang dialect, and Chengdu is also influenced by some Nanlu dialects.

In recent years, he conducted voice survey in Huguang dialect areas, such as East Sichuan and North Sichuan, and found that some villages spoke Nanlu dialects because when Zhang Xianzhong massacred in Sichuan in that year, people survived because of the inconvenience of traffic in mountainous areas, so the dialect was also preserved and became a "dialect island". Zhou Jixu (2016) also found that although Suining speaks Huguang dialect now, Li Shi, a Suining native, wrote Shu dialect in Suining dialect, which is actually Nanlu dialect. "Shu Language" was written before Zhang Xianzhong entered Sichuan, so it further confirms his point that before Zhang Xianzhong entered Sichuan, Sichuan dialect was the world of Nanlu dialect.

The two most dominant levels of szechuensis, subdivided into branches, clusters, and sheets, are clearly distributed with two major levels, Minjiang starting from Dujiangyan downwards to Geshan, Yibin,
Luzhou, which are roughly alphabetical L-shaped. To the East and North are Huguang languages, represented by Chongqing languages in Chengdu, while to the West and to the south are Nanlu languages, such as Dayi, Qionglai, Yibin and Leshan.

The dialects of different places migrated to Sichuan and could not communicate with each other, so they had to compromise with each other and try to imitate the official language that everyone could understand when communicating, so they eventually blended into the present kind of Sichuan dialect: most people could roughly understand it, and gradually moved closer to the northern mandarin.

Outbreaks of the Anti-Japanese War catalysed the tendency to generalize dialects. With the fall of Northeast and North China, Japan invaded Myanmar and the southwest region, originally the rear area, quickly became a new strategic center. During this period, a large number of immigrants and government officials, military forces entered Yunnan, Guizhou and Sichuan, bringing with them vocabulary transformed from dialects and foreign languages all over the country. The author's grandmother left Jilin with her family in 1937, entered the customs from Shaanxi Province, fled all the way to Chongqing, and then settled in Chongqing. My grandfather, on the other hand, was native to Chengdu, and the dialects spoken by them were already differentiated from those of my mother and my aunt, so that the difference was mostly not reflected in the phonetic tone but in the lexical paraphrase. Until my generation, some semantics completely disappeared, replaced by Mandarin vocabulary, such as the concept of "queue" which was called "platoon wheel" in Chongqing dialect about 30 years ago, but now becomes "queue" in Mandarin. Also for example when my father said about my experience of going up a mountain with him in early childhood, said that by himself mentioning two pairs of "opening hills" that opened up a weed growing old road for me, I and peers did not wonder, and only after his interpretation combined with the context learned that "opening hills" referred to an axe. My parents often exclamate that my Chongqing dialect no longer sounds like a native Chongqing person, and the main reason for this is that the dialect vocabulary is gradually assimilated by the Mandarin vocabulary.

A survey in Baidu Dialect Postbar in June 2020 showed that Southwest Mandarin seems to be the most widely recognized dialect. Although this is a spontaneous survey by the people, although the data sources are not authoritative enough, it can prove that the popularization of Southwest Mandarin has reached the point that even netizens are aware of.

The table below lists all the meanings of sit in Sichuan Dialect Dictionary, Guiyang Dialect Dictionary and Kunming Dialect Dictionary. The above dictionaries were all written around the 1990s, and the Sichuan 
Dialect Dictionary was revised in 2014, which is basically equivalent to today's Southwest Mandarin.

Table 2 A collection of terms for "sit" contained in the Southwest Mandarin Dialect Dictionary

\begin{tabular}{|c|c|}
\hline Sense item & Example sentence \\
\hline Difficulty, trip & You asked me to sit on a candle. \\
\hline Nursing for women one month after delivery & She's still in confinement and can't go down. \\
\hline Modify the way or place of drinking and tea. & Today, instead of guessing a fist, we'll have a drink. \\
\hline Imprisoned in prison & Sit in prison \\
\hline $\begin{array}{l}\text { A business with a fixed place of business, equivalent to } \\
\text { a "merchant" }\end{array}$ & Go into business \\
\hline $\begin{array}{l}\text { The bedside table in the form of wooden box can hold } \\
\text { things or sit and rest }\end{array}$ & Sitting box \\
\hline $\begin{array}{l}\text { "Back List", that is, at the end of the result list after an } \\
\text { exam }\end{array}$ & be the last of a number of successful candidates \\
\hline live & $\begin{array}{l}\text { Where do you sit? } \\
\text { Rent a room to sit. } \\
\text { <Proverb>The oil lady rubs her head with water, the butcher's } \\
\text { wife bites her bones, and the skilled carpenter sits in a } \\
\text { wooden building. }\end{array}$ \\
\hline rest & Take a seat. \\
\hline Quantifiers, mostly for large or fixed objects & A bridge;A tower. \\
\hline $\begin{array}{l}\text { Molar teeth, on both sides behind the mouth, with } \\
\text { verrucous bulges on the crown for grinding food }\end{array}$ & Seat teeth \\
\hline A clock placed on a table, as distinct from a wall clock & Desk clock \\
\hline Refers to animal nesting behavior & Do (sit) nest \\
\hline Where to sit is different from a single seat & $\begin{array}{l}\text { There isn't even a seat here.Go! In front is my friend's house. } \\
\text { Go there and find a bench to sit down and talk. }\end{array}$ \\
\hline Meat on the hips of pigs & Sitting pie meat \\
\hline A metaphor for being a leader and leading a job & $\begin{array}{l}\text { "All the crops in three ditches and one dam are mine?" Wang } \\
\text { Dafei then asked. "But you are sitting on the altar! " several } \\
\text { voices shouted at the same time. }\end{array}$ \\
\hline In a dilemma & $\begin{array}{l}\text { On the request of a gentleman of Chengdu, it was of course } \\
\text { possible to push off, not to be sure, and to be left with a } \\
\text { temporary dressing and to hold on to Zhao Erfeng for sitting } \\
\text { wax. }\end{array}$ \\
\hline confirm & $\begin{array}{l}\text { When going on now, dressed again as a Sichuan gentleman, } \\
\text { it was fine that brother Zhao would certainly sit and hold his } \\
\text { nose breathed the same as the Sichuan brothers. }\end{array}$ \\
\hline Sit in a teahouse & $\begin{array}{l}\text { Little or nothing has been dragged off the sitting water table } \\
\text { to eat the coverbowl tea to be reviewed, as has the penalty of } \\
\text { a writhing tax. }\end{array}$ \\
\hline Gossip, chat & $\begin{array}{l}\text { The old woman also simply, where she brought things, the } \\
\text { eldest sister never despised, but also carried them to her } \\
\text { yard to sit. }\end{array}$ \\
\hline $\begin{array}{l}\text { Tapping drum; Play a conductor role in the Sichuan } \\
\text { Opera Band }\end{array}$ & $\begin{array}{l}\text { The drummer is a wizard. He is the only one in the town who } \\
\text { can sit in a bucket. }\end{array}$ \\
\hline Sedentary endurance & $\begin{array}{l}\text { Zhao Shaode is rash, not obedient, not good at sitting, and } \\
\text { not a good material for being a waiter. }\end{array}$ \\
\hline seat & $\begin{array}{l}\text { The other three parties are large and heavy benches, which } \\
\text { are the booths for the ready-to-go wine sales. }\end{array}$ \\
\hline
\end{tabular}

\subsection{On the Influence of the Dialect Word "sit" in Southwest Mandarin on the Composition of Modern Chinese Dictionary}

The following is a detailed explanation of the meaning of "sit" in the modern Chinese dictionary (7th edition)

1) 把臀部放在椅子、登子或其他物体上，支持身 体重量。泛指以臀部着物而止息: 请坐。咱们坐下来 谈。他坐在河边钓鱼。席地而坐。坐待。坐垫。坐骨。
坐化（佛教指和尚盘膝坐着死去）。坐禅。坐功。坐 骑。

1) Support body weight by putting your hips on a chair, stool, or other objects. Generally referred to as stopping with something on your buttocks: Please sit down. Let's sit down and talk. He sat by the river fishing. Sit on the ground. Wait. Cushion. Ischium. Sitting (Buddhism refers to a monk sitting on his knees and dying). Sit in meditation. Sitting Meditation. Ride.

2) 乘; 搭: 坐船。坐火车。 
2) Take; By: by boat. by train.

3) (房屋) 背对着某一方向: 这座大楼是坐北朝 南的。

3) (house) to the side: the building was sitting north to the south.

4) 把锅、壶等放在炉火上: 坐一壶水。火旺了, 快把锅坐上。

4) Put pots, pots, etc. on the fire: sit on a pot of water. When the fire is hot, put the pan on.

5）（坐儿）同“座”

5) (Seat) same "Seat"

6) 因......犯罪, 触犯法律。

6) Crime for ..., offenders law.

7）枪炮由于反作用而向后移动; 建筑物由于基础 不稳固而下沉: 步枪的坐劲儿不小。这房子向后坐了。

7) The gun moves backwards due to reaction; Buildings sink due to unstable foundations: the sitting strength of the rifle is not small. The house sits back.

8）瓜果等植物结实：坐果。坐瓜。

8) Fruits and other plants bear fruit: fruit setting. Melons Sitting.

9）指定罪：连坐。反坐。

9) Designated guilt: sitting in company. Seat back.

10）形成（疾病）：打那次受伤之后, 就坐下了 腰疼的病根儿。

10) Formation (sickness): After that injury, he sat down at the root of the lumbar pain.

11 ）表示无缘无故: 孤蓬自振, 惊砂坐飞。

11) Indicates that there is no reason: the canopy is self-oscillating and the sand is fluttering.

12）坚守, 引申为常驻, 不动: “楚人坐其北门, 而覆诸山下”。坐庄。

12) Hold fast, extend to permanent residence, do not move: "Chu people sit at the north gate and cover the mountains."Sitting on a villa.

13 ) 物体向后施压力: 房顶往后坐。

13) Pressure on the object backwards: the roof sits back.

14）介词, 因, 由于, 为着: “停车坐爱枫林晚, 霜叶红于二月花”。

14) Prepositional, because, due to, for: 'Stop and sit in the night of love maple forest. The frost leaves are red than the flowers in February'.

15）副词
15) Adverbs

a. 空，徒然，如“胡为坐自苦，吞悲仍抚膺”;

a. Empty, in vain, such as "Hu suffers for sitting down, swallowing sadness and still caressing";

b. 无故, 自然而然, 如“如若此, 则盐必坐长十 倍”;

b. For no reason, naturally, such as "if so, the salt will sit ten times longer";

c. 遂，即将，如“寒英坐销落，何用慰远客”;

c. Then, soon, such as "What can you use to comfort the thoughts of distant friends when you see that the plum blossoms are about to fade?"

d. 深, 如“感此伤妾心，坐愁红颜老”;

d. Deep, as in "seeing this scenario I'm sad and thus sad aged. "

e. 正，恰好，如“西村渡口人烟晚，坐见渔舟两 两归”。

E. Just as it happens, "In the evening, the number of people at the mouth of the river in Xicun decreases and the fishing boat just comes back to the port in three, two or two times."

16）诉讼时在法官面前对质。《左传·昭公二十三 年》: “晋人使与制大夫 ”

16) Confront a judge during a lawsuit. 《Zuo Zhuan · the 23rd year of Zhaogong $\rangle:$ :Jin envoys and Dr. Ying "

Until the 1950s, domestically published dictionaries were paraphrased in plain words, detached from popular spoken reality, and used with great effect. In such cases, the Language Institute of the Chinese Academy of Sciences decided to compile a medium-sized modern lexicon. There are two ways to compile a lexicon: one is self editing (an explanatory or illustrative illustration needs to be designed by itself according to word order paraphrasing and usage.), and the other is book evidence, that is, the work of excellent writers and the extraction of natural examples from computer corpora, in which the role of self compiled illustration is similarly to supplementary illustrative semantics, and it has the advantages of more purposeful illustration, not influenced by episodic context, not bending, cutting directly into the subject matter, rehearsal of words, and saving space. While the disadvantage is due to the difficulty of self editing example sentences, some sentences have raw marks, and the sentence style varies from one editor to another. As for book evidence, there is evidence of the objective existence of a word order and semantics, demonstrating the source stream evolution of semantics, illustrating the provenance of semantics and complementing the role of illustrative 
semantics and usage. In our country, since the 1920s, there have been scholars to build corpora of texts, but corpora of earlier years are not machine-readable and of small size, so the greatest difficulty the editors encounter is that there is no kind of lexicon that can be referenced, and everything starts at zero. Prior to its formal preparation, the dictionary editorial office carried out data collection from 1989 to 1989 by ticking words from modern Chinese books, press, magazines all over the country where they could be obtained, which naturally also included information from the area where the South Western authorities belong.1, ,2), 4, ,5), 5), 7) the paraphrases in the seventh edition of the modern Chinese lexicon overlap with those commonly used since recent times in the southwestern languages. When compiling a dictionary, the editing room may want to include as many different meanings of the same character as possible in Mandarin dialects. With the change of Southwest Mandarin, new vocabulary will be included and outdated vocabulary will be deleted.

\section{INVESTIGATION AND ANALYSIS OF VERB "SIT" IN FOUR DIALECT POINTS OF MODERN SOUTHWEST MANDARIN}

The following table is the survey data of verb "sit" in four dialect points of modern Southwest Mandarin.

Table 3 Survey Data of Verb "Sit" in Four Dialect Points of Modern Southwest Mandarin

\begin{tabular}{|c|c|c|c|c|}
\hline Usage of the Verb "Sit" & $\begin{array}{l}\text { Chongqing } \\
\text { (Yubei District) }\end{array}$ & $\begin{array}{l}\text { Chengdu } \\
\text { (Qingyang } \\
\text { District) }\end{array}$ & $\begin{array}{l}\text { Guiyang (Yunyan } \\
\text { District) }\end{array}$ & $\begin{array}{c}\text { Kunming (Panlong } \\
\text { District) }\end{array}$ \\
\hline Please have a seat & + & + & + & + \\
\hline Take a sedan chair & + & + & + & + \\
\hline There's nothing to sit on & + & + & & + \\
\hline by boat & + & + & + & + \\
\hline be in prison & + & + & + & + \\
\hline Confinement & + & + & + & + \\
\hline \multicolumn{5}{|l|}{ Official sitting in court } \\
\hline Sit there (where) & + & + & + & + \\
\hline Sitting family & & + & + & \\
\hline Sitting position & + & + & + & \\
\hline Not sitting properly & + & + & & \\
\hline Pull the mount on & + & + & & \\
\hline Lamp seat & + & + & + & \\
\hline Sit the water open & & + & & \\
\hline $\begin{array}{l}\text { The stitches hold the } \\
\text { paint tight }\end{array}$ & & + & & \\
\hline Seedling basket & & & + & \\
\hline $\begin{array}{l}\text { The price of rice is } \\
\text { sitting }\end{array}$ & & + & & \\
\hline $\begin{array}{l}\text { Sit down over the } \\
\text { house }\end{array}$ & & + & + & \\
\hline
\end{tabular}

With respect to the last term, the respondents in Guiyang provided two different claims. With respect to the last term, the respondents in Guiyang provided two different claims. We speculate that there are two reasons for this situation: one is that the Chinese character corresponding to the oral syllable can not be found in the corpus, so the expression of sit is used; The second is that, as the capital city, Mandarin promotion, combined with the resident of a large number of migrants from various locations after the founding period, forms a large change from the new town, the words of noble (mainly old urban areas), to the old-fashioned words.

"Riding on horses", "sitting on official halls", "sitting on rice paddles", "seating on paint with seams" and other usages have disappeared in three of the four urban areas mentioned above, not only because population movements have made a language no longer pure, but also because it is an evolution of natural selection. The meaning of its representation then disappears after the occult nature of the thing itself. Nowadays, we have not seen, in the city, any seedling growing in the fields, not to mention the hall where the old time officials sat.

\section{COMMONALITY OF SEMANTIC EVOLUTION OF "SIT" FROM CROSS-LINGUISTIC PERSPECTIVE}

Sit, as one of the most basic meaningful actions of living organisms, often appears in various semantic maps. Semantic map is a geometric expression of 
functions in a "concept / semantic space", such that functional models (constructs) exhibited with the aid of a map form are pervasive, while node arrangement on maps by this cross linguistic comparison tool maps corresponding concepts or structures in the cognitive hearts of humans. If a certain form of meaning has multiple meaningful uses that are repeatedly loaded in the same several forms in different languages, it may reflect some linguistic similarities of human cognition. Studies by Ga. I. Custova and Lai. Yo. Rozina show that the subject category of a vocabulary predicts its derivative potential and ultimately determines the aggregate of ambiguity. There are up to 13 conceptual fields related to "sit" in the Worldwide Language Synonymization Online Database, and five of them are underlined in Southwest Mandarin. This suggests that the meaning of many verbs is indeed an interconnected hierarchy with commonalities across geographic isolation, across cultural differences, and a manifestation of similarities in biomechanism.

DWELL (LIVE, RESIDE) 居住

SIT DOWN 坐下
REMAIN 存留
CROUCH 屈膝, 蜷伏 (一种蹲下的姿势)
RIDE 骑, 乘坐
BE ALIVE 存活
SET (HEAVENLY BODIES) 放置 (重物)

EAT 吃

BE ALIVE OR LIFE 活着/生命

STAND 站立

LIE DOWN 躺下

HAVE 拥有

\section{CHAIR 座位}

It follows that the commonalities of human language are greater than those of individuality.

\section{Conclusion}

In the past half century or more, vast language writers have turned their minds to the construction of standardization of Chinese and defined the standard of Mandarin, so that Chinese can be comprehensively adapted to the need of full-name learning and to the need of sociopolitical, economic, scientific, and cultural development. Since the beginning of the 21 st century, the whole country has been working together to achieve a well-off society, taking Putonghua as the common language of the Chinese nation. Indeed, an effciently functioning and colorful society cannot leave the expression of language, and it is essential to create advanced cultures that inherit the traditional culture of excellence, nor is it free of language, so that economic leap development can be more independent of the normative and standard language for communicating information, maintaining operations, and driving circulation. Similarly, with the gradual and widespread promotion of Mandarin, as well as the intensification of population movements due to rapid economic development, the status of dialects around has occurred and continues to change.

In the southwest region, mandarins have an increasing space for survival and have even been introgressed into southwestern mandarins on the square side. Without reference to age, a survey with the words "local dialect" can separate generations from old to young, from counties to cities. But while seeing outstanding results from Mandarin promotion, we also have to worry about the future of southwestern mandarins. As a cultural carrier of water and soil, if dialect is no longer itself, but a common language which has changed its tone, can it also become a carrier of culture? Will China's extensive and profound national culture also tend to be mediocre with the unification of the North-South tune? In my opinion, the establishment of dialects corpora has reached the point where there is no delay. This can not only enrich the theoretical methods of the comparative study of Chinese dialects vocabulary, but also enrich the research contents of our China's folksonology, culture, sociology, and so on, and contribute significantly to the study of Chinese dialects, but also to the study of the history of Chinese and promote the standardization of modern Chinese vocabulary. Although this study only draws a superficial conclusion on the term sit, that is, the definition and usage of sit not only changes with the historical changes in Southwest China, but also influences the investigation and research of modern Chinese lexicology to a certain extent, it does enrich a linguistic point in semantics by interviewing native speakers of dialects and consulting materials extensively. It is expected to provide more detailed data and evidence for the future study of Southwest Mandarin vocabulary.

\section{CITATION SOURCES}

[1] Catalogue of Chongqing Local Journals Office (Eds.). Integration of Local Journals of All Dynasties in Chongqing, Beijing: National Library Press, 2020.

[2] Li Rong (Ed.). Chengdu Dialect Dictionary, Nanjing: Jiangsu Education Press, 1998.

[3] Peng Jing (Ed.). Communication Dictionary, Shanghai: Shanghai Dictionary Publishing House, 2013.

[4] [Canada] Omar L. Keird. English is a perfect match for century old Sichuan Dialect--- 1917. New 
explanation of the first year students in West China using Chinese textbooks. Translations by Zhang Shiguang, Yuan Tingdong, Liu Jian, Lei Kang, Chengdu: Tiandi Publishing House, 2016.

[5] Wen Duanzheng, Wen Shuobin. Theory and Practice of Language Coding, Beijing: Business Press, 2014.

[6] Wang Wenhu, Zhang Yizhou and Zhou Jiayun (Eds.). Sichuan Dialect Dictionary, Chengdu: Sichuan People's Publishing House, 1986.

[7] Wang Ping (Ed.). Guiyang Dialect Dictionary, Nanjing: Jiangsu Education Press, 1994.

[8] Yang Yuerong (Ed.). The Local Chronicle of Chongqing city (Dialects), Chongqing: Chongqing Publishing House, 2012.

[9] Adam Grainger. Western Mandarin, or the Spoken Language of Western China, Notes by Yang Wenbo et al., Shanghai: Shanghai University Press, 2016.

10] You Rujie. Bibliography of Chinese dialectology works of Western missionaries, Harbin: Heilongjiang Education Press, 2002.

[11] Hua Wen Zhang et al. (Ed.). Kunming dialects dictionary, Kunming: Yunnan Educational Press, 2006.

\section{REFERENCES}

[1] Cui Rongchang. Formation of Sichuan dialect [J]. Dialect, 1985 (1): 6-14.

[2] Du Xiaoli. Talking about a Sichuan dialect dictionary compiled by missionaries - "Xishu Dialect"[J]. Journal of Sichuan Minzu College, 2011,20(6): 51-55.

[3] Han Chang, Rong Jing. A lexical typological study of the verb "sit"[J]. Journal of Chinese Teaching in the World, 2019,33(4): 504-521.

[4] Wang Xiaoyang. Russia's "Dynamic Model of Vocabulary Semantics" has received wide attention [N]. Chinese Social Sciences Today, 7th Edition, February 1, 2016.

[5] Xiang Xuechun. Study on Ancient Dialects and Words Seen in Shu Dialect--Also on the relationship between migrants and Sichuan dialects [J]. Linguistic Sciences, 2010,9(3): 317-323.

[6] Yang Huilin. Grammar and Culture of Textbooks for First Year Students in West China $[\mathrm{J}]$. Sino-American Journal of Humanities, 2018 (02): 79-90.

[7] Zhou Min, Zhou Jixu. Seeing the Change of Sichuan Dialect from the Vocabulary of Shu in Ming
Dynasty [J]. Linguistic Research, 2016 (3): 23-26.

[8] Lakoff, G., \& M. Johnson. Metaphors We Live By[M]. Chicago: University of Chicago Press, 1980. 